\title{
Ixeris dentata (Thunb) Nakai Attenuates Cognitive Impairment in Scopolamine-induced Amnesic Mice
}

\author{
Sung-Gyu Lee ${ }^{1}$, Ki-Whan Kim ${ }^{2}$ and Hyun Kang ${ }^{1, \dagger}$ \\ ${ }^{I}$ Department of Medical Laboratory Science, Dankook University, Cheonan-si, Chungnam 31116, Korea \\ ${ }^{2}$ Department of R\&D Center, C.L.Pharm CO., Ltd., Seoul 04788, Korea
}

\begin{abstract}
The purpose of the current study is to investigate the cognition-enhancing effects of Ixeris dentata (Thunb) Nakai in scopolamine-induced amnesic mice. Scopolamine ( $2 \mathrm{mg} / \mathrm{kg}$, i.p.) was used to induce amnesia in mice. The cognitiveenhancing activity of the IDE $(10,20$ and $40 \mu \mathrm{g} / \mathrm{mL})$ was studied by passive avoidance response, elevated plus maze and Y-maze behavioral paradigm in normal and scopolamine-induced amnesic mice. Scopolamine-induced cognitive deficits were significantly reversed by IDE $(P<0.001$ at $20 \mathrm{mg} / \mathrm{kg})$ in a dose-dependent fashion in all the behavioral paradigms tested. IDE possesses cognitive-enhancing properties in amnesic mice due to its potent antioxidant action.
\end{abstract}

Key Words: Ixeris dentata, Cognition, Scopolamine, Antioxidant, Amnesia

Cognition in a broad sense means the ability of the brain to encode, store and retrieve information (Im et al., 2006). The hippocampus contains the neural circuitry crucial for cognitive functions such as learning and memory, and intellectual aspects of mental functioning (Asuntha et al., 2010). Cognitive dysfunction, a major health problem in recent times can negatively affect learning and memory skills of individuals leading to the pathogenesis of various neurodegenerative disorders (Derell, 1996). Ixeris dentata var. albiflora Nakai, from the family Astaraceae, is a medicinal herbal plant used traditionally in Asian countries to treat stomach upsets, diabetes, tumors and liver diseases (Satyanarayana et al., 2004; Ahn et al., 2006). Pharmacologically, I. dentata has been reported to possess anti-mutagenic, anti-cancer, hypoglycemic, hypocholesterolemic and oxidative stress inhibiting properties (Hong et al., 2010; Kim et al., 2002;
Choi et al., 1990). However, the cognitive-enhancing effect of I. dentata in scopolamine-induced amnesic mice. In the present study, we evaluated cognitive-enhancing effects of I. dentata extract (IDE) in scopolamine-induced amnesic mice models.

All chemicals used were of analytical grade including scopolamine butyl bromide (SBB), 2 deoxy-D-ribose, thiobarbituric acid, nitro blue tetrazolium and riboflavin were purchased from Sigma Chemical Company, St. Louis, MO, USA. Plant material and preparation of I. dentata extract. We followed our previous work on use of plant material and preparation of I. dentata extract (Lee et al., 2016). Animals Male C57BL/6 mice (22 25 g, 8-week-old) were obtained from Orient Bio Co. (Seoul, Korea). They were housed in groups of five under standard conditions with food and water ad libitum. All experiments were performed under the guide-

\footnotetext{
* Received: September 12, 2017 / Revised: September 26, 2017 / Accepted: September 26, 2017

${ }^{\dagger}$ Corresponding author: Hyun Kang. Department of Medical Laboratory Science, College of Health Science, Dankook University, Cheonan-si, Chungnam 31116, Korea.

Tel: +82-41-550-3015, Fax:+82-41-559-7934, e-mail: hkang@dankook.ac.kr

(C) The Korean Society for Biomedical Laboratory Sciences. All rights reserved.

(C) This is an Open Access article distributed under the terms of the Creative Commons Attribution Non-Commercial License (http://creativecommons.org/licenses/by-nc/3.0/) which permits unrestricted non-commercial use, distribution, and reproduction in any medium, provided the original work is properly cited.
} 
lines of Principles of Laboratory Animal Care (NIH publication No.85-23, 1985) and Dankook University Institutional Animal Care and Use Committee.

The mice were divided into five groups $(n=15)$, i.e., vehicle, scopolamine (2 mg/kg), IDE (40 mg/kg), sopolamine + IDE $10 \mathrm{mg} / \mathrm{kg}$, sopolamine + IDE $20 \mathrm{mg} / \mathrm{kg}$ and sopolamine + IDE $40 \mathrm{mg} / \mathrm{kg}$. Different doses of IDE were prepared freshly by dissolving in distilled water and administered for 15 days through oral gavage (p.o.). Scopolamine was prepared in normal saline. On the 15 th day, after 60 min of administration of doses, acquisition trail for passive avoidance and the transfer latency for elevated plus maze was recorded. On the next day, 60 min after administration of IDE at various doses, amnesia was induced by administration of scopolamine ( $2 \mathrm{mg} / \mathrm{kg}$, i.p.) and animals were tested for their memory tests $30 \mathrm{~min}$ after scopolamine administration. For the passive avoidance test, s step through type passive avoidance test apparatus (GEMINI, Model PACS-30, San Diego instruments Int., USA) was used to evaluate the effects of extract on learning and memory as described previously (Moon et al., 2009).

For the Y-maze task Immediate working memory performance was assessed by recording spontaneous alternation behavior during a single session in a Y-maze. Each arm was $40 \mathrm{~cm}$ long, $12 \mathrm{~cm}$ wide and $30 \mathrm{~cm}$ high. The procedure was similar as described previously (Kumar et al., 2012). The animal was allowed to explore the maze for $10 \mathrm{~s}$ and was then returned to its home cage. Memory retention was examined $24 \mathrm{~h}$ after the first day trial (Kasture et al., 2007). All data are presented as mean \pm SEM. Statistical analysis was performed with SAS statistical software (SAS Institute, Cray, NC, USA) using one-way analysis of variance, followed by Dunnett's tests. $P<0.05$ was considered statistically significant.

IDE extract attenuated the cognitive and behavioral impairments in MPTP-induced mouse model in our group studies (unpublished data). The enhanced cognitive and behavioral function exhibited by IDE extract treatment was strongly supported by the reduced brain oxidative stress in MPTP-induced mice. In the present investigation IDE showed significant inhibition of cognitive deficits observed in scopolamine-induced amnesic mice. As shown in Fig. 1,

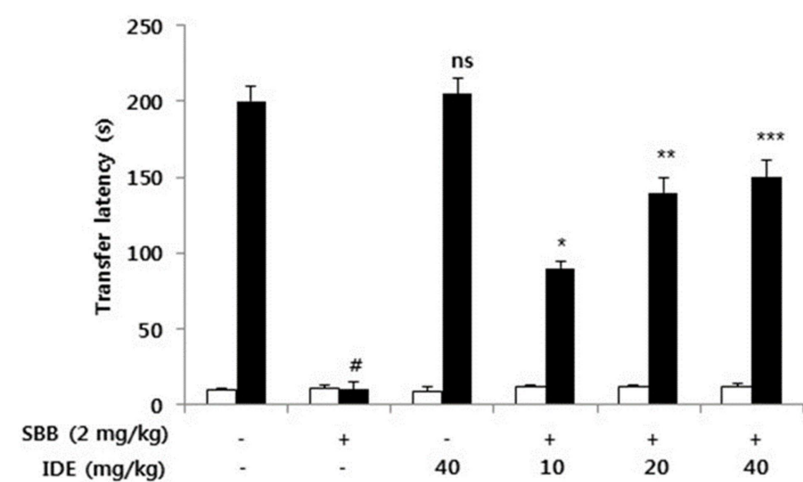

Fig. 1. Effect of IDE on scopolamine-induced amnesia in passive avoidance test. Memory impairment was induced by scopolamine $(2 \mathrm{mg} / \mathrm{kg}$, i.p.) $5 \mathrm{~min}$ before acquisition (Trial I), and retention (Trial II) was carried out $24 \mathrm{~h}$ after scopolamine treatment. $\square$ : Acquisition, $\mathbf{\square}$ : Retention. $\# P<0.001$ compared with control group. NS: Not significant. $* P<0.05,{ }^{* *} P<0.01$ and $* * * P<0.001$ compared with scopolamine group. Data is expressed as mean \pm S.E.M. $(\mathrm{n}=5)$ using one-way ANOVA followed by Tuckey's Multiple comparison test in the Graph Pad Prism v 5.01 software. SBB: Scopolamine butyl bromide; IDE: I. dentata aqueous extract

Transfer latency was significantly increased on the second trial (207.4 $\pm 11.7 \mathrm{~s})$ when compared with first trial (13.9 $\pm 1.2 \mathrm{~s}$ ) in control-trained group, but in scopolaminetreated group there was no significant increase on second trial $(16.75 \pm 2.91 \mathrm{~s})$ when compared with first trial (17.61 $\pm 2.9 \mathrm{~s})$. IDE treated alone group $(40 \mathrm{mg} / \mathrm{kg}) \mathrm{did}$ not influence the TLT and was similar to control group. Pretreatment with different doses of IDE (10, 20 and $40 \mathrm{mg}$ / $\mathrm{kg})$ for 15 days increased the TLT on second trial (101.02 \pm $23.17 \mathrm{~s}$ for $10 \mathrm{mg} / \mathrm{kg}, 146.13 \pm 15.62 \mathrm{~s}$ for $20 \mathrm{mg} / \mathrm{kg}$ and $175.36 \pm 20.62 \mathrm{~s}$ for $40 \mathrm{mg} / \mathrm{kg}$ ) when compared with first trial $(20.81 \pm 6.1 \mathrm{~s}, 20.3 \pm 3.5 \mathrm{~s}$ and $22.81 \pm 10.41 \mathrm{~s})$, respectively in amnesic mice.

Cognitive impairment is one of the major health problems and a characteristic symptom of several neurodegenerative disorders including Alzheimer's disease (AD) and Parkinson's disease (PD) (Kim et al., 2002). Antioxidant supplements and phytochemical components might be helpful for preserving brain functions and forestalling neurodegeneration (Blum et al., 2001; Kang et al., 2014). Thus, agents that scavenge free radicals and regulate oxidative defense mechanisms may have potential in the mitigation of cognitive dysfunction 


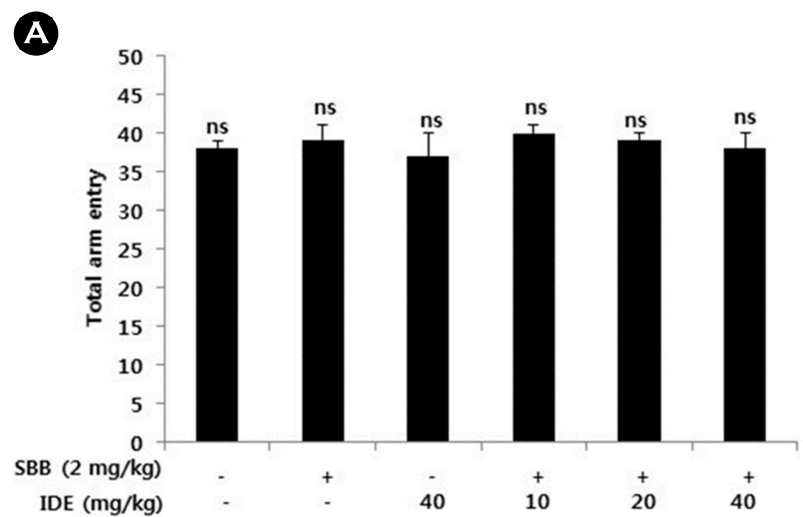

B

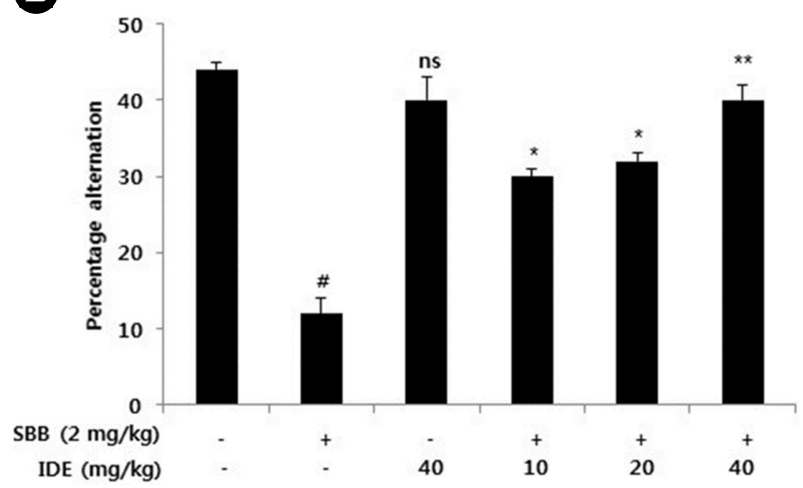

Fig. 2. Effect of IDE on scopolamine-induced memory deficits in the Y-maze test. Spatial working memory was assessed using YMaze. Memory impairment was induced by scopolamine treatment $(2 \mathrm{mg} / \mathrm{kg}$, i.p.), and the test was carried out $30 \mathrm{~min}$ later. Total Arm entry (A) and percentage alternation (B) was evaluated. $\# P<0.001$ compared with control group. NS: Not significant. ${ }^{*} P<0.05$ and ${ }^{*} * P<0.01$ compared with scopolamine group. Data is expressed as mean \pm SEM $(n=5)$ using one-way ANOVA followed by Tuckey's Multiple comparison test in the Graph Pad Prism v5.01 software. SBB: Scopolamine butyl bromide; IDE: I. dentata aqueous extract

seen in neurodegenerative diseases. In our previous work we presented data on the. The suppression of NF- $\mathrm{kB}$ activation pathways (Lee et al., 2016). Further, the antioxidant actions of IDE might also be involved in delivering such potent anti-neuroinflammatory actions. Therefore, IDE can be developed as a therapeutic agent in the treatment of neurodegenerative disease.

It is well documented that scopolamine induction impairs retrieval of memory in experimental animals and such amnesia is associated with a significant increase in oxidative stress (El-Sherbiny et al., 2003). Therefore, scopolamine

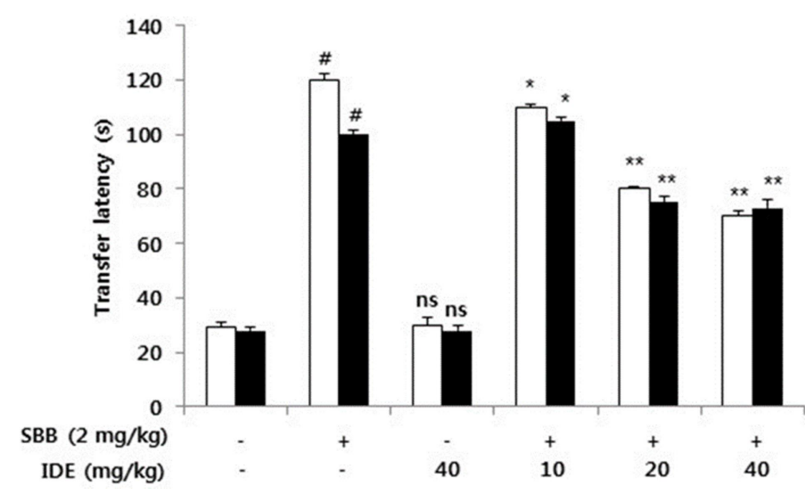

Fig. 3. Effect of IDE on scopolamine-induced memory impairment in mice using the elevated plus maze test. Transfer latency in seconds was measured in first trial second trial. $\square$ : Acquisition, 口: Retention. $\# P<0.001$ compared with control group. NS: Not significant. $* P<0.05$ and $* * P<0.01$ compared with scopolamine group. Data is expressed as mean \pm S.E.M. $(n=5)$ using one-way ANOVA followed by Tuckey's Multiple comparison test in the Graph Pad Prism v5.01 software. SBB: Scopolamine butyl bromide; IDE: I. dentata aqueous extract

induced amnesia could be used as a valid model to study the role of antioxidant defense mechanisms in cognitive dysfunctions. The data indicate a dose-dependent effect, with $40 \mathrm{mg} / \mathrm{kg}$ showing the highest activity. There was no significant difference in TLT in the first trial among various groups. The findings from passive avoidance test suggest that IDE at various doses $(10,20$ and $40 \mathrm{mg} / \mathrm{kg})$ showed increase in TLT in retention trial of passive avoidance. As shown in Fig. 2A, there was no significant difference observed in total arm entry of any group. However, administration of scopolamine $(2 \mathrm{mg} / \mathrm{kg}$, i.p) significantly $(P<0.001)$ decreased the percentage alternation $(25.07 \pm 2.16 \mathrm{~s})$ when tested 30 min after the administration in mice Fig. 2B. Pre-treatment with IDE at indicated doses (10, 20 and $40 \mathrm{mg} / \mathrm{kg}$, p.o.) ameliorated the scopolamine-induced decreased percentage alternation in mice significantly $(P<0.05$ at 10 and $20 \mathrm{mg} /$ $\mathrm{kg}$ and $P<0.01$ at $40 \mathrm{mg} / \mathrm{kg}$ ). Results indicated that IDE exhibited a dose dependent activity with $40 \mathrm{mg} / \mathrm{kg}$ exhibiting the highest effect (48. $32 \pm 0.75 \mathrm{~s})$. Cognitive behavior evaluated through Y-maze test suggests an improvement in percentage alteration behavior in IDE treated groups against scopolamine-induced amnesia in a dose dependent manner. The scopolamine treated group showed a significant increase 
$(P<0.05)$ in transfer latency $(\mathrm{TL})$ values in the acquisition $(141.72 \pm 10.62 \mathrm{~s})$ as well as the retention period (117.34 $\pm 7.13 \mathrm{~s}$ ) over those of the vehicle control mice, indicating impairment in learning and memory (Fig. 3).

Pretreatment with IDE at various doses (10, 20 and 40 $\mathrm{mg} / \mathrm{kg}$ ) for 15 days improved the memory in the elevated plus maze. IDE administration dose dependently $(P<0.5$, $P<0.01$ and $P<0.001$ at 10,20 and $40 \mathrm{mg} / \mathrm{mL}$ respectively), caused a significant reduction in the acquisition and retention latency in scopolamine-treated group with $40 \mathrm{mg}$ / $\mathrm{mL}$ showing the highest effect (acquisition, $73.52 \pm 4.15 \mathrm{~s}$ and retention, $67.13 \pm 3.91 \mathrm{~s})$. The elevated plus maze test revealed that IDE showed protective effect in TL against scopolamine-induced amnesia dose-dependently. Moreover, the decrease in TL during retention period indicate the positive response of IDE in attenuating learning and memory deficits induced by scopolamine. The major active constituents of $I$. dentata contained approximately $4 \mathrm{mg} / \mathrm{g}$ of caffeic acid (3,4-dihydroxy cinamic acid) (Kim et al., 2013). Approximately 20 types of sesquiterpene and other compounds have been isolated from $I$. dentata. It has been reported that its main compounds are luteolin, luteolin 7O-glucuronide, caffeic acid, chlorogenic acid, and guaiane sesquiterpene lactones (Cha et al., 2011). Among these main compounds, inhibitory effects of luteolin, chlorogenic acid, and tectroside on allergic inflammation had already been reported. The major active components of I. dentata are phenolic constituents (Kim et al., 2013). These compounds might act individually or in a synergistic manner in delivering neuroprotective effect.

\section{ACKNOWLEDGEMENTS}

This research was supported by the Ministry of Trade, Industry \& Energy (MOTIE), Korea Institute for Advancement of Technology (KIAT) through the Encouragement Program for The Industries of Economic Cooperation Region).

\section{CONFLICT OF INTEREST}

No conflicts of interest, financial or otherwise, are declared by the authors.

\section{REFERENCES}

Ahn E, Bang M, Song M. Cytotoxic and ACAT inhibitory sesquiterpene lactones fromthe root of Ixeris dentata forma albiflora. Archives of Pharmacal Research. 2006. 29: 937-941.

Asuntha G, Prasannaraju Y, Prasad KVSRG. Effect of ethanol extract of Indigofera tinctoria Linn. (Fabaceae) on lithium/ pilocarpine-induced status epilepticus and oxidative stress in Wistar rats. Tropical Journal of Pharmaceutical Research. 2010. 9: 149-156.

Blum D, Torch S, Lambeng N. "Molecular pathways involved in the neurotoxicity of 6-OHDA, dopamine and MPTP: contribution to the apoptotic theory in Parkinson's disease", Progress in Neurobiology. 2001. 65: 135-172.

Cha MR, Choi YH, Choi CW, Yoo DS, Kim YS, Choi SU. New guaiane sesquiterpene lactones from Ixeris dentata. Planta Medica. 2011. 77: 380-382.

Choi JS, Chung HY, Young HS. A preliminary study on hypocholesterolemic and hypoglycemic activities of some medica plants. Korean Journal of Pharmacognosy. 1990. 21: 153-155.

Derrell C. Guide for the care and use of laboratory animals. Institute of laboratory animal resources. National Academy Press. 1996

El-Sherbiny DA, Khalifa AE, Attia AS, Eldenshery ED. Hypericum perforatum extract demonstrates antioxidant properties against elevated rat brain oxidative status induced by amnestic dose of scopolamine. Pharmacology Biochemistry and Behavior 2003. 76: 525-533

Hong S, Jeong D, Kim K, Hwang E. The Composition of the root of Ixeris dentata var. albiflora Nakai. and cell viability and DPPH radical scavenging activities of its extract. Korean Journal of Nutrition. 2010. 43: 105-113.

Im HI, Lee ES, Hwang YJ, Kim YS. Baicalein protects 6-OHDAinduced neuronal damage by suppressing oxidative stress. The Korean Journal of Physiology and Pharmacology. 2006. 10: 309-315.

Kang H. Anti-neuroinflammatory effects of Ixeris dentata Nakai against lipopolysaccharide-induced BV-2 microglial cells via suppressing NF-кB Signaling. Tropical Journal of Pharmaceutical Research. 2014. 13: 1629-1635.

Kasture SB, Kasture VS, Joshua AJ. Damodaran A, Amit A Nootropic activity of BacoMind ${ }^{\mathrm{TM}}$, an enriched phytochemical composition from Bacopamonnieri. Journal of Natura 
Remedies. 2007. 7: 166-173.

Kim DS, Ko JH, Jeon YD, Han YH, Kim HJ, Poudel A. Ixeris dentata NAKAI reduces clinical score and HIF-1 expression in experimental colitis in mice. Evidence-Based Complementary and Alternative Medicine. 2013. 67: 1281-1289.

Kim MJ, Kim JS, Jeong DM, Ham SS, Yu CY. Effect of antioxidant, antimutagenicity and anticancer of root extract from Ixeris dentata Nakai. Korean Journal of Medicinal Crop Science. 2002. 10: 222-229.

Kim SB, Kang OH, Joung DK, Mun SH, Seo YS, Cha MR. Antiinflammatory effects of tectroside on UVB induced $\mathrm{HaCaT}$ cells. International Journal of Molecular Medicine. 2013. 31 : 1471-1476.

Kumar H, Kim BW, Song SY, Kim JS, Kim IS, Kwon YS, Koppula S, Choi DK. Cognitive enhancing effects of alpha asarone in amnesic mice by influencing cholinergic and antioxidant defense mechanisms. Bioscience, Biotechnology, and Biochemistry. 2012. 76: 1518-1522.

Lee SK, Kang H. Ixeris dentata (Thunb) Nakai Ethylacetate extract attenuates sterol regulatory element-binding proteins- $1 \mathrm{c}$ via
AMP-activated protein kinase activation. Tropical Journal of Pharmaceutical Research. 2016. 15: 453-459.

Moon M, Kim HG, Hwang L, Seo JH, Kim S, Hwang S, Kim S, Lee D, Chung H, Oh MS, Lee KT, Park. Neuroprotective effect of ghrelin in the 1-methyl-4-phenyl-1,2,3,6-tetrahydropyridine mouse model of Parkinson's disease by blocking microglial activation. Neurotoxicity Research. 2009. 15: 332 -347 .

Satyanarayana S, Sushruta K, Sarma GS, Srinivas N, Subba Raju GV. Antioxidant activity of the aqueous extracts of spicy food additives--evaluation and comparison with ascorbic acid in in-vitro systems. Journal of Herbal Pharmacotherapy. 2004. 4: $1-10$.

https://doi.org/10.15616/BSL.2017.23.3.281

Cite this article as: Lee SG, Kim KW, Kang H. Ixeris dentata (Thunb) Nakai Attenuates Cognitive Impairment in Scopolamine-induced Amnesic Mice. Biomedical Science Letters. 2017. 23: 281-285. 